\title{
Modelling the Heating Process in Simultaneous Laser Transmission Welding of Semicrystalline Polymers
}

\author{
Christian Hopmann and Suveni Kreimeier \\ Institute of Plastics Processing (IKV), RWTH Aachen University, 52074 Aachen, Germany \\ Correspondence should be addressed to Suveni Kreimeier; suveni.kreimeier@ikv.rwth-aachen.de
}

Received 31 July 2016; Revised 12 September 2016; Accepted 19 September 2016

Academic Editor: Yeong-Soon Gal

Copyright ( 2016 C. Hopmann and S. Kreimeier. This is an open access article distributed under the Creative Commons Attribution License, which permits unrestricted use, distribution, and reproduction in any medium, provided the original work is properly cited.

\begin{abstract}
Laser transmission welding is an established joining process for thermoplastics. A close-to-reality simulation of the heating process would improve the understanding of the process, facilitate and shorten the process installation, and provide a significant contribution to the computer aided component design. For these reasons a thermal simulation model for simultaneous welding was developed which supports determining the size of the heat affected zone (HAZ). The determination of the intensity profile of the laser beam after the penetration of the laser transparent semicrystalline thermoplastic is decisive for the simulation. For the determination of the intensity profile two measurement systems are presented and compared. The calculated size of the HAZ shows a high concordance to the dimensions of the HAZ found using light microscopy. However, the calculated temperatures exceed the indicated decomposition temperatures of the particular thermoplastics. For the recording of the real temperatures during the welding process a measuring system is presented and discussed.
\end{abstract}

\section{Introduction}

Since the 1980s, laser transmission welding of plastics parts plays an increasing role in industrial mass production due to advancements in process and machine technology. For example, for welding of vibration sensitive components, where conventional techniques meet their procedural limits, the benefits of laser transmission welding become apparent [1-3].

Extensive research on thermal modelling of laser transmission welding has been presented since the mid-1990s. Parallel to the first industrial applications of the laser transmission welding, the analytical description of the heating phase was analyzed [4-8]. To be able to make these calculations, several simplifications had to be accepted regarding the optical properties of the welding partners, the scattering of the laser light, or the temperature dependence of the material properties. The first comprehensive thermal modelling of the laser transmission welding process using analytical methods was performed by Russek [9]. Comparing the experimental and simulated results of contour and simultaneous welding tests, a good accordance could be shown. However, a statement regarding to what extent the calculated temperatures match the real temperatures is still missing.

First approaches to leverage a finite element analysis (FEA) as a numerical simulation of the heating phase during laser transmission welding can be found in [5,10-19]. Grewell and Benatar, for example, presented the implementation of a coupled squeeze flow and intermolecular diffusion model, which was used to predict the quality and size of micro welds in thermoplastics. The simulation results had a good accordance with the experimental values, although there was some deviation between the experimental data and the simulation model for different parameters. Grewell and Benatar stated that this was due to the temperature-dependent material properties as well as optical aberrations [16]. Mayboudi et al. present a three-dimensional unsteady thermal model of the laser transmission welding process solved using FEA. Their thermal model includes the heating and cooling stages in a laser welding process with a shifting laser beam considering the heat conduction along the beam travel direction [17]. 


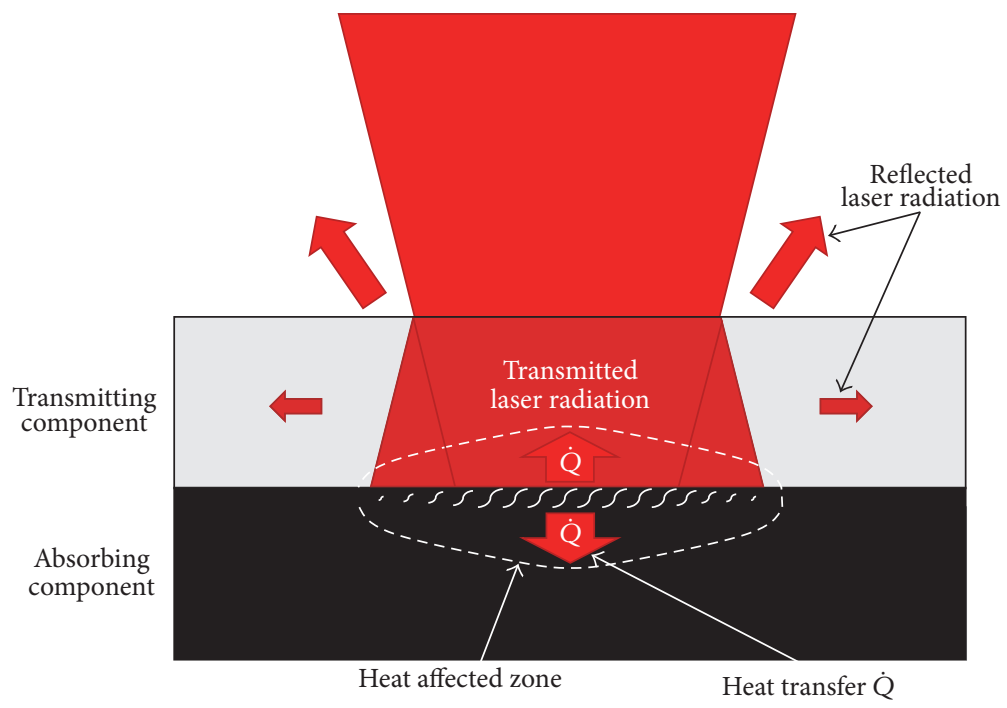

FIGURE 1: Principle of radiation fluxes during laser transmission welding.

In [20] the thermal simulation model for the calculation of the temperature distribution in the weld seam during the laser transmission welding process of thermoplastics is presented. One focus of this paper is the topic of "determining the energy input in the welding zone during welding." Therefore measurements with a spectrometer were compared to measurements with an integrating sphere. For the measurements with the integrating sphere, a new measurement setup is presented. Furthermore the topic "optical interfaces" is considered for portraying the simplifications which have been made in the simulation. Finally a first attempt for a thermomechanical simulation has been presented. Based on the calculated temperature distribution, thermally induced residual stresses have been calculated.

Today still most of the model simplifications are made regarding the input parameters in the simulation. As a result, based on the thermal model in [20], here temperaturedependent material properties and the influence of the degree of crystallinity on the optical properties are considered in the heating simulation. In addition significant effort was spent to determine these material properties experimentally. In order to determine the shape of the intensity distribution of the laser beam after passing the laser transparent part, two measurement systems are introduced. Moreover, a measuring system to determine the maximum temperature in the weld line is presented.

\section{Principle of the Laser Transmission Welding}

In laser transmission welding the heating of two plastics parts and the joining operation of the two partners occur in a single step [21-23]. For this reason the welding technique of laser transmission welding requires joining partners with different optical properties. One joining partner is required to have a high transmittance for the laser radiation, whereas the other one needs to have a high absorbance at the wavelength of the laser. In Figure 1 the process is shown schematically.
The laser radiation irradiates the laser transparent joining partner and is absorbed and converted into thermal energy near the surface of the laser-absorbing partner. This results in heating up the material above the melting temperature. The heat transfer in the joining zone ensures an indirect plasticizing of the laser transparent partner [24].

\section{Influences on the Laser Transmission Welding Process}

There is a series of factors (e.g., the laser wave lengths) which have a major influence on the laser transmission welding process. The material properties have the major effect on the process, based on the optical properties like the inner structure (amorphous or semicrystalline) and the amount of additives and pigments. In order to achieve a high and reproducible weld seam quality, also the geometric boundary conditions like the design of the joint area, the thickness of the laser transparent joining partner, or the components' tolerances have to be considered $[25,26]$. In addition, the welding parameters are of particular importance for the quality of the joint. In this regard, the following parameters have to be mentioned especially $[9,27]$ :

(i) Laser power

(ii) Energy density or energy input per unit length

(iii) Joining pressure

(iv) Power density/laser intensity distribution

(v) Process variant

The optical properties are of decisive importance for the laser welding process as the radiation's intensity is reduced due to interactions with the material when the radiation penetrates a medium [28-31]. 


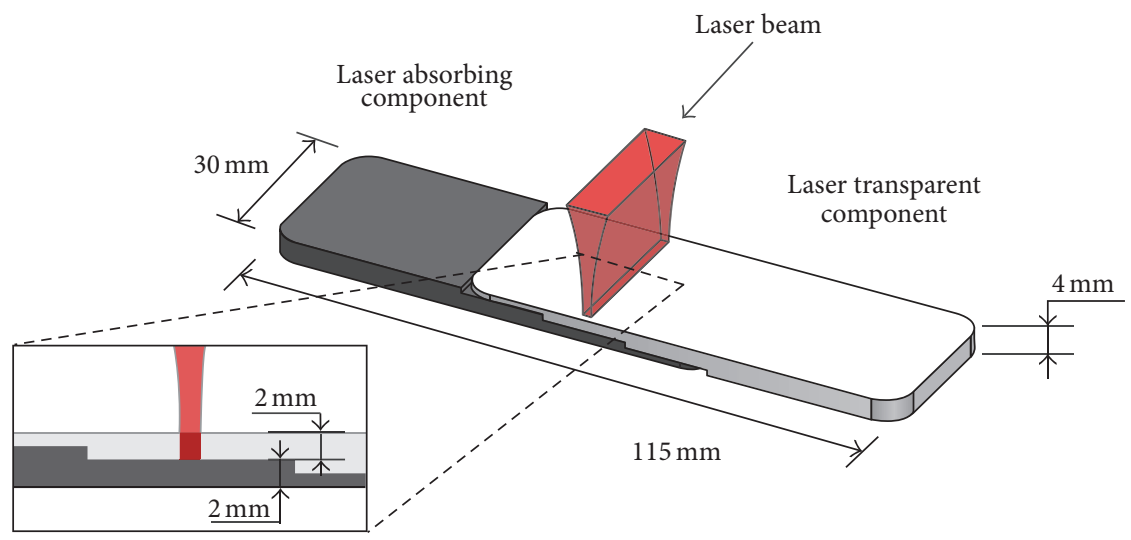

Figure 2: Specimen.

\section{Researched Materials and Applied Experimental Setup}

Since the influences of scattering semicrystalline thermoplastics on the laser transmission welding process are not negligible, experiments are performed with the following semicrystalline polymers: polyamide 66 (PA 66, Ultramid A3W, BASF SE, Ludwigshafen/Germany), polypropylene (PP, HD120MO, Borealis AG, Vienna/Austria), and polybutylene terephthalate (PBT, Ultradur B4520, BASF SE, Ludwigshafen/Germany).

The specimens are injection molded step blocks (Figure 2) with four different thicknesses $(1,2,3$, and $4 \mathrm{~mm})$. The step which is irradiated is $2 \mathrm{~mm}$ thick.

During the experiments the process variant simultaneous welding is performed, where a rectangular focused laser beam $\left(1.5 \times 27 \mathrm{~mm}^{2}\right)$ irradiates the material. In the course of the experiments the laser power $P_{L}$ and the irradiation time $t_{L}$ are varied as welding parameters.

Six parts are welded for each parameter combination. The two laser systems LDF 400-90 $\left(P_{L, \max }=90 \mathrm{~W}\right)$ and LDM 400$40\left(P_{L, \max }=400 \mathrm{~W}\right)$ are high-power diode lasers supplied by Laserline $\mathrm{GmbH}$, Mülheim-Kärlich, Germany. Both devices emit laser radiation at a wavelength of $\lambda=940 \mathrm{~nm}$.

The joining tests are evaluated using a tensile-shear-test according to DIN ISO 527 [13] and microscopy images. The microscopy images should illustrate the welding zone between the joining partners and the dimensions of the HAZ.

\section{Determining the Shape of the Energy Density Distribution after Passing the Laser Transparent Part}

For the modelling of the laser transmission welding process the intensity profile of the laser spot when hitting the absorbable layer is crucial. The exact determination of the shape of the transmitted intensity distribution is of high importance. Different approaches to determine the intensity profile can be found in [32-37]. Becker and Potente describe measurements of the power flux distribution at the weld interface after passing through a $5 \mathrm{~mm}$ thick sample of unreinforced polypropylene. A near Gaussian radial power flux is obtained and the incoming beam diameter is significantly spread [34]. Zak et al. present a technique for measuring the scattering of the laser beam caused by the laser transparent part. An easy way to determine the intensity profile for contour welding is presented [37]. The exact determination of the intensity profile is decisive for the quality of the simulation results. For these reasons, two systems (FocusMonitor, Spiricon Camera) for the determination of the intensity profile of line focus optics are presented and compared in this paper.

The FocusMonitor (Primes GmbH, Pfungstadt, Germany) measures the intensity profile with a rotating measuring tip which scans the laser spot line-by-line. At the measuring tip is a small point like opening, where the radiation is forwarded to the detector inside the device using a mirror system (Figure 3). During the measurement the prevalent intensity in dependence of the angle and line is recorded. Using these data the device calculates an overall picture of the laser spot, whereas the pixels can have relative intensity values from 0 to 4096. During this "static" measurement the measuring range of the FocusMonitor has a size of $24 \times$ $12 \mathrm{~mm}^{2}$ with a resolution of $256 \times 256$ pixels. There is the possibility of a "dynamic" measurement for increasing the measuring range. In this setup the measuring tip rotates in one line, while the laser moves over it. The resulting recording can be converted into a $2 \mathrm{D}$-picture using the rotational speed of the measuring tip and the traverse speed of the laser

In both measuring procedures the sample is positioned on top of the case of the FocusMonitor, while, equivalent to the welding process, the laser is focused on the bottom of the sample. In this process the distance $H=4 \mathrm{~mm}$, shown in Figure 3(b), exists between the measuring layer and the sample. Depending on the scattering behavior of the sample, an expansion of the transversal intensity profile occurs, which results in a distortion of the measurement. The necessity of dynamic measuring of the linear spot is another disadvantage caused by the small range of the device. The dynamic measurement results in additional work and 


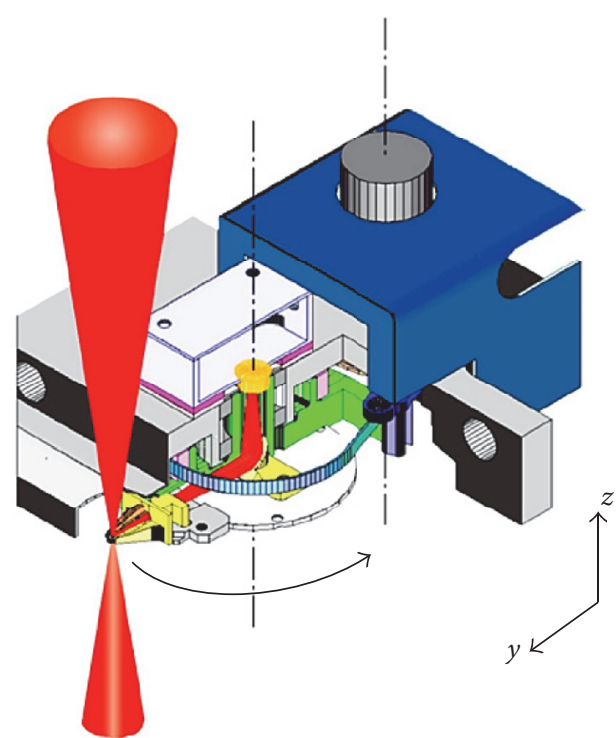

(a)

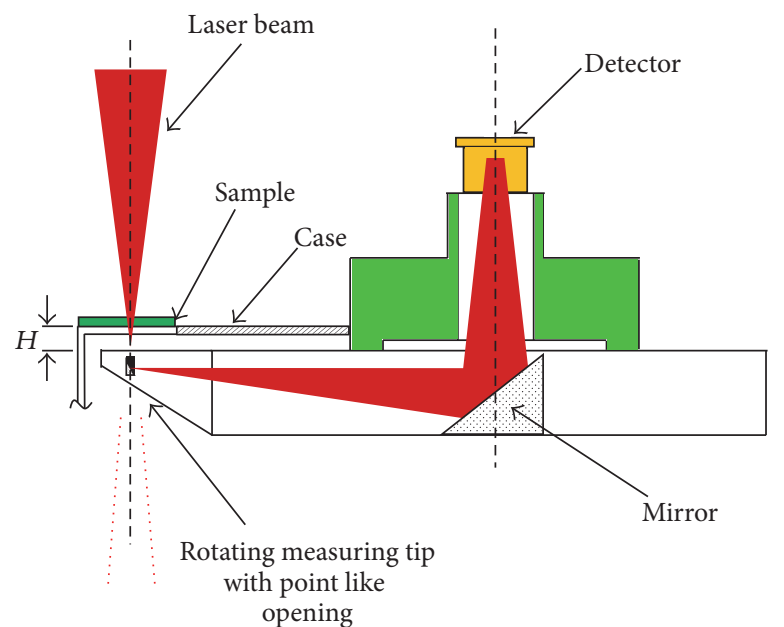

[NN13]

(b)

FIGURE 3: Design of the FocusMonitor for the measurement of the intensity profile of the laser spot [42].

adds further uncertainties regarding the rotational speed of the measuring top and the transversal speed of the laser.

The Spiricon SP620U (Ophir Optronics Solutions Ltd., Jerusalem, Israel) is a USB camera based on a CCD-sensor. The CCD-sensor is equipped with $1600 \times 1200$ pixels on an active area of $7.1 \times 5.4 \mathrm{~mm}^{2}$ and reacts to light between $190 \mathrm{~nm}$ and $1100 \mathrm{~nm}$. In combination with the CCTV-lenskit the SP620U functions like a conventional camera and allows the filming of a picture layer. Intensity values from 0 to 4096 are assigned to each pixel, which correlate linear with the real intensity values. The objective is equipped with a dimming function and a manual focus facility, which serve as a fine adjustment. The schematic setup is established with neutral density filters and spacers between the objective and the sensor. Thus the choice of the combination of neutral density filters and spacers determines the magnification ratio, the object distance, and the exposure of the sensor [38].

With the described configuration the intensity profile cannot be captured directly, but merely the radiation emitted over a diffuse spreading area. Ideally this area complies with the bottom of the laser transparent sample, while the laser is focused on this layer, equivalent to the welding process. However, the diffuse spreading behavior of the semicrystalline samples does not satisfy the requirements of the camera. For this purpose an opal glass is set up beneath the sample, which is equipped with a diffuse spreading area. The resulting measuring setup is schematically shown in Figure 4. The camera is mounted vertically beneath the sample and focused on the coated area of the opal glass. The focusing takes place using a halogen spotlight, which illuminates a paper which is positioned on the opal glass for this purpose. A writing or another sharp structure on the paper serves as a reference when setting up the objective. The camera is connected via
USB to a Windows computer, which controls the camera with the software BeamMic. The recordings of the camera are subjected to the so-called natural edge lighting effect. This effect results in a reduction of the measured intensity on the edge of the recording and requires a mathematical correction of the results.

The comparison of both measurement methods would lead to the conclusion that the measuring setup using the SP620U is much more suitable for the determination of the intensity profile needed for the simulation. The larger measuring area and the identical measuring layer in the welding process can be stated out as decisive advantages. To keep the workload low, the comparison is reduced to the parameters width $W$ and the boundary range $B$ of the intensity profile (Figure 5).

For the comparison, the cross sections of the intensity profile of ten experiments are replicated, centered over the spot. The results are contrasted in Figure 6, showing the median and the range. It appears from the diagram that the results of the FocusMonitor are generally and specifically with highly spreading samples, such as PA66 and PBT, afflicted with a higher measurement uncertainty. These results strengthen the choice of the SP620U for the modelling of the welding process. Furthermore, the records partially indicate significant material dependent differences, which do not follow a consistent trend. Using the FocusMonitor, the expected beam expansion, resulting from the distance of the measuring layers, can only be confirmed for PA66 but not for PP. When measuring PA66, the widths of the linear spot differ by approx. $40 \%$, which is why a significant higher power density in the welding area in the optimized model can be expected. In particular the influence of the used opal glass has to be mentioned, which has not been examined yet and should be analyzed in further studies. 


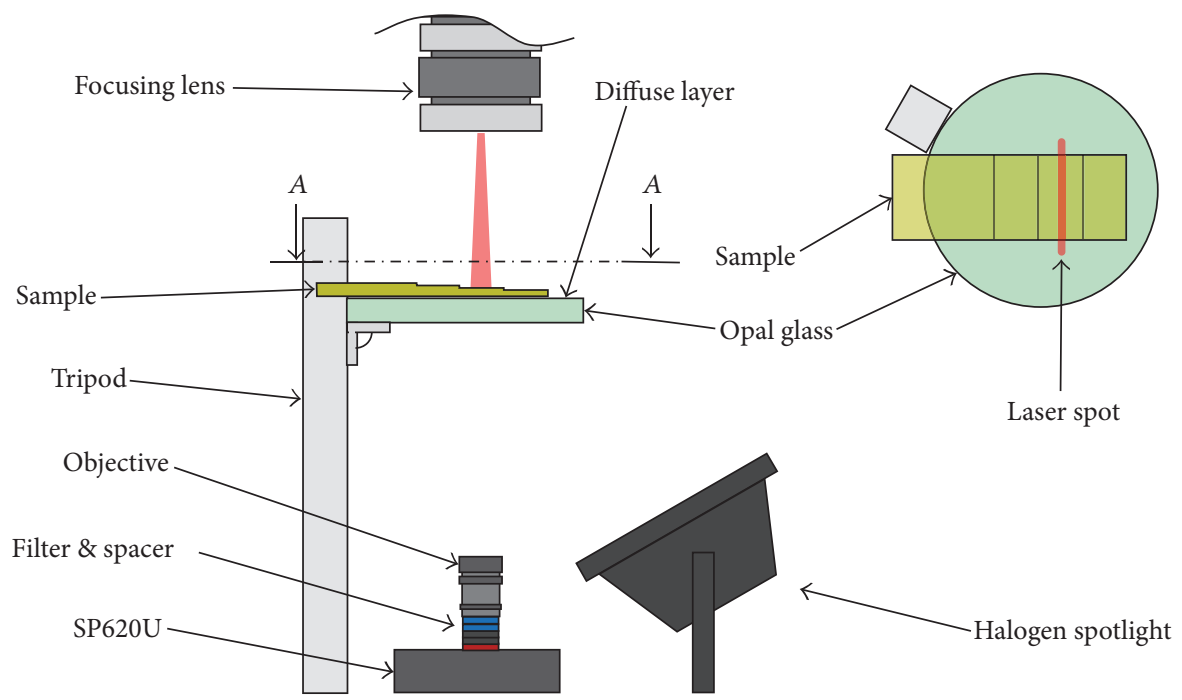

FIGURE 4: Measuring setup of the Spiricon for the determination of the intensity profile of the laser spot.

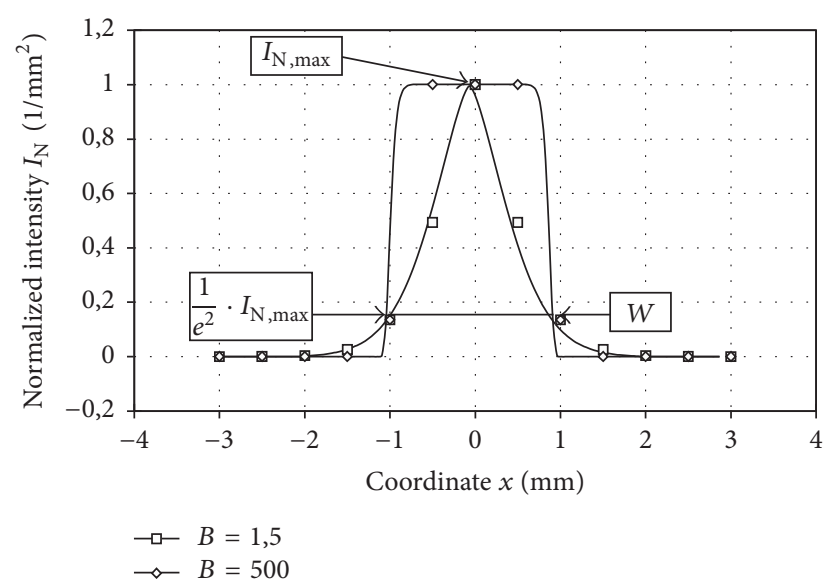

FIGURE 5: Width $W$ of the intensity profile and influence of the boundary range $B$ on the intensity profile.

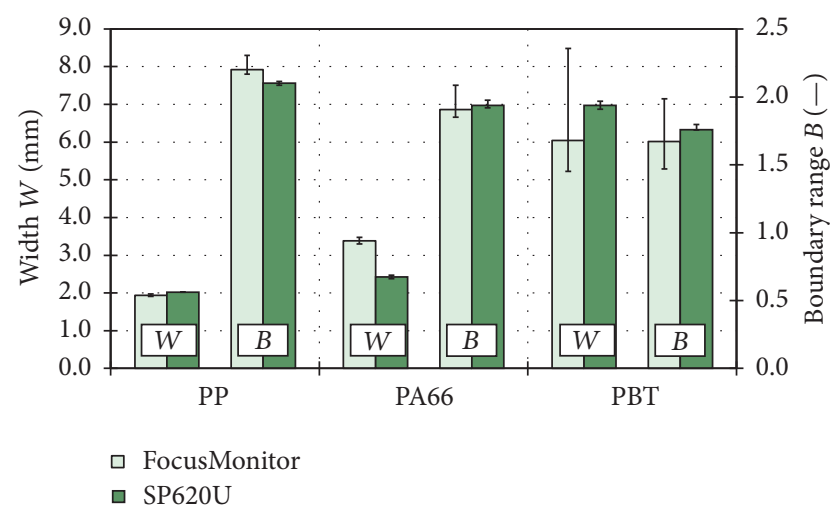

FIGURE 6: Comparison of the measuring results of FocusMonitor and Spiricon.

\section{Modelling the Heat Transfer Process during Laser Transmission Welding}

After several steps of experimental quantification of scattering on the laser beam caustic and intensity distribution, a finite element model was implemented for the purpose of thermal process simulation $[20,23,30,31]$. The thermal calculations are carried out using the FE simulation program Abaqus by Dassault Systèmes Simulia Corp., Rhode Island, USA. The elaborated two-part simulation model consists of one upper and one lower joining partner. During simultaneous welding there is no relative movement between the processing optics and the joining member. This means that it is not necessary to implement any movement of the laser beam in the calculation model either. Within the implemented model the temporal and spatial fluctuating temperature fields are calculated on the basis of the general differential equation of thermal conduction according to Fourier:

$$
\rho(T) \cdot c_{p}(T) \cdot\left(\frac{\partial T}{\partial t} \cdot(\nabla \vec{v}) T\right)=\Delta(\lambda \cdot T)+\dot{Q}^{\prime \prime \prime} .
$$

Within (1) $T$ is the temperature which has to be calculated depending on the time $t$ and the spatial coordinates $x, y$, and $z$, while $\rho, c_{p}$, and $\lambda$ are material properties. The material properties of the transparent material are assigned to the upper joining partner and those of the absorbing material to the lower joining partner. The properties to be allocated are material-specific and temperature-dependent and must be determined for the utilized materials. The following material properties are required: density $\rho$, specific heat capacity $c_{p}$, and thermal conductivity $\lambda$. Apart from this the absorption coefficient $\alpha$ of the laser transparent and laser-absorbing partner and also the heat transfer coefficient $h$ must be determined. 

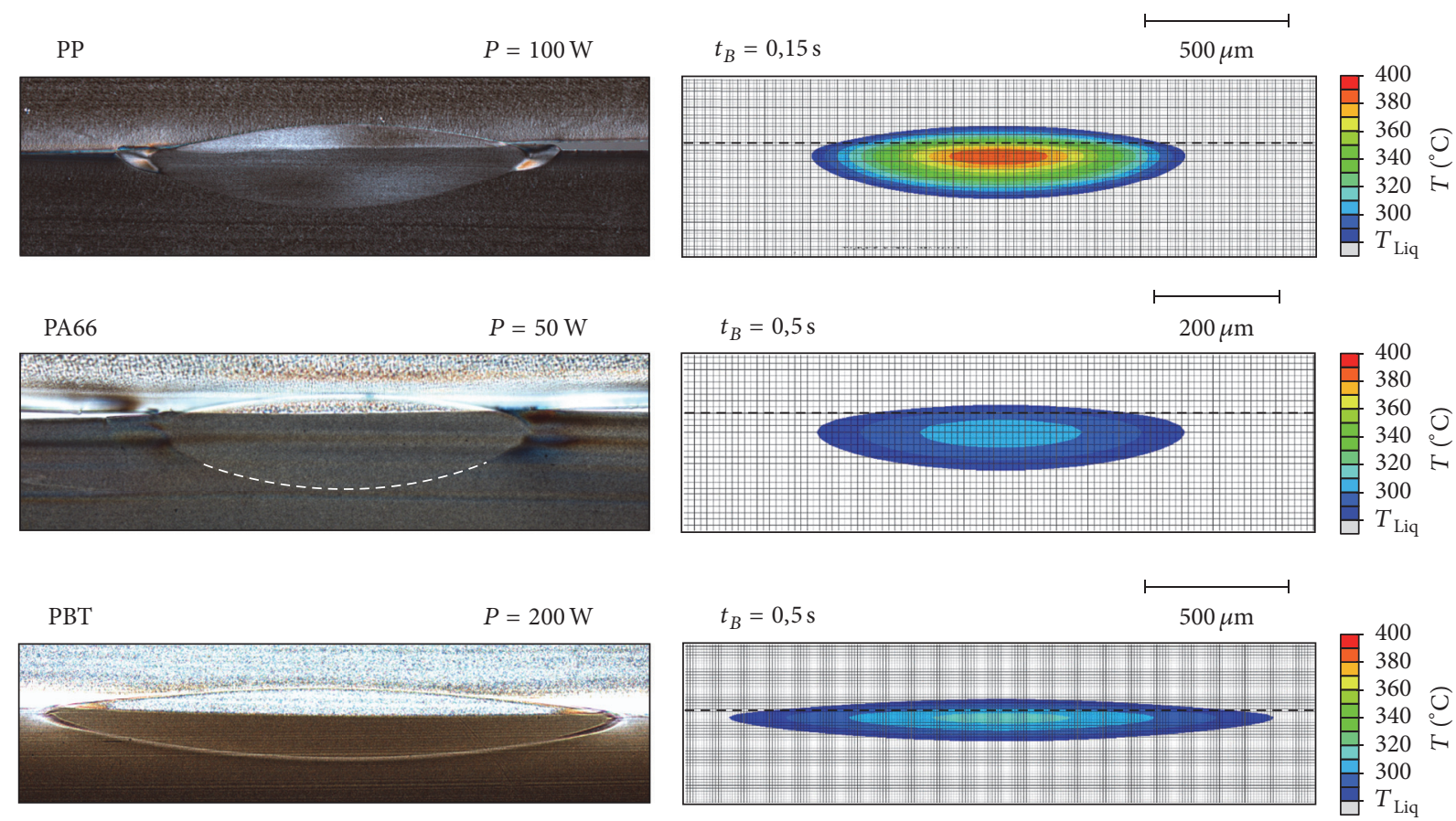

FIgURE 7: Validation of the simulation model based on the optical appearance of the HAZ.

Neglecting heat transfer in $z$-direction (depth) because of a rectangular focused beam, the direction of the incident laser beam, (1) can be simplified as follows:

$$
\rho(T) \cdot c_{p}(T) \cdot \frac{\partial T}{\partial t}=\nabla(\lambda \cdot \nabla T)+\dot{Q}^{\prime \prime \prime}
$$

The volume heat source $\dot{Q}^{\prime \prime \prime}$ representing the laser beam and some of the regarded aspects of the laser beam matter interaction within (2) can be described as shown by (3), while it is assumed on basis of determined values:

$$
\dot{Q}^{\prime \prime \prime}=A(y) \cdot \tau_{G} \cdot\left(1-\rho_{\mathrm{abs}}\right) \cdot e^{-\varepsilon_{t} \cdot d} \cdot P \cdot \mathrm{amp} \cdot e^{-2|x / r|^{B}}
$$

with $A(y)=\alpha \cdot e^{-\alpha \cdot(y-d)}$.

Within (3) $\dot{Q}^{\prime \prime \prime}(x, y)$ is the intensity distribution of the laser beam in Cartesian coordinates, which is fitted to the above discussed experimental data. $A(y)$ is a function, which depends on the absorption coefficient $\alpha$ of the treated material. The absorption coefficient $\alpha$ depends on the coordinate $y$ (thickness), the material thickness $d$, and the material's local as well as temporal changing temperature $T$. The transmittance of the laser transparent component is considered with $\tau_{G}$ and $\rho_{\text {abs }}$ includes the surface reflection of the material. $\varepsilon_{t}$ is the extinction coefficient, which describes the attenuating radiation behavior of the material. The laser power is considered with $P$ and the amplitude of the intensity distribution with amp. Furthermore $B$ is the boundary range and $r$ is the radius of the boundary range. According to these equations, the volume heat source $\dot{Q}^{\prime \prime \prime}$ is implemented using FORTRAN code.
After its implementation the model is used to calculate the weld seam width $W$, its height $H$ depending on the process parameters radiation time $t_{B}$, and laser power $P$.

The calculations for simultaneous welding were carried out with a two-dimensional model in order to reduce the calculation duration without losing relevant information about the dimension of the HAZ. In order to validate the calculations, the heat affected zone heights $H$ and widths $W$ of welded test specimens are determined using thin sections and were correlated with calculated isotherms of the melting temperature at the end of the radiation exposure duration since the isotherms correspond to the completely molten region. One effect which arises with semicrystalline materials is the inhomogeneity or random arrangement of the crystals. Thus, the formation of the HAZ is afflicted with a deviation with regard to the dimensions because of the different transmittance factors from component to component. Since the dimensions of the heat affected zone serve to validate the simulation results, it is necessary to determine the standard deviation of these values for statistical substantiation. Thus, it is necessary to consider a tolerance window for assessing the real welds in comparison to the simulation.

In Figure 7, only the completely molten region is portrayed in color. All the regions which are below the melting temperature $\left(T_{S}=265^{\circ} \mathrm{C}\right)$ are portrayed in grey. The dashed line represents the joining plane. The temperature distributions portray the condition at the end of the radiation exposure duration. Long radiation exposure durations and high powers lead to large energy input into the material. As a rule, the heat affected zone therefore becomes larger with an increasing radiation exposure duration or power, that is, more material is melted completely. The qualitative comparison of 


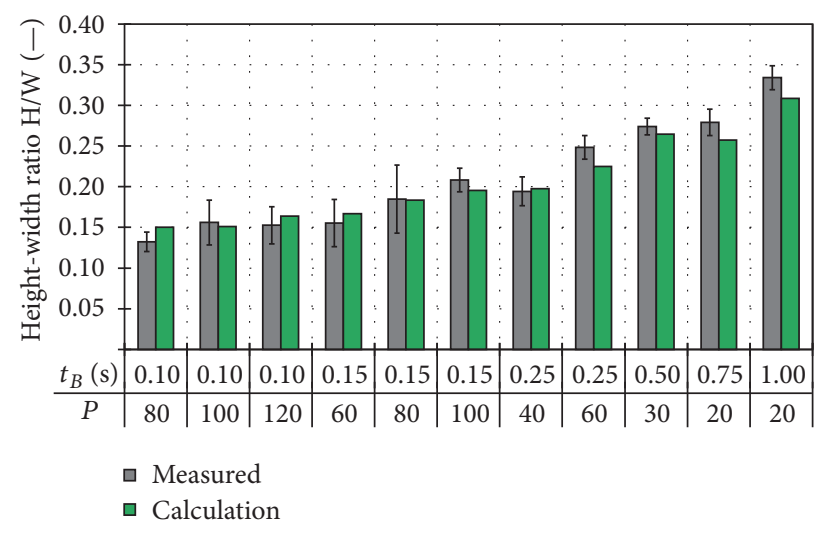

FIGURE 8: Comparison of calculated HAZ with measured weld dimensions in the simultaneous welding process for PP.

the experimentally measured and the calculated HAZ proves the validity of the elaborated model for laser beam transmission welding. Figure 7 portrays this optical comparison for the HAZ for various materials and different laser welding parameters.

The comparison shows that the results of the simulation regarding the optical appearance of the HAZ for PP, PA66, and PBT-particularly with regard to the elliptical shapeare close to reality.

For a detailed analysis a quantitative comparison of the HAZ regarding the sizes of the HAZ is performed. The comparison of the height-width ratio of the HAZ is shown in Figure 8. In general, there is a good match between the calculated and the measured dimensions. The match for PP is significantly better than for PA66 [20]. This indicates that there is a potential for improvement when modelling highly scattering materials such as PA66.

\section{Measuring the Maximum Temperature in the Heat Affected Zone}

For the validation of the calculated results the real HAZ are measured and their sizes and shapes are compared. However, in the simulation, temperatures higher than the decomposition temperature are calculated during the welding process. The capture of the absolute temperature distribution during the laser transmission welding process is of major interest.

In laser transmission welding process the heating of the polymer takes place in the range of milliseconds. The maximum temperatures are not maintained for long, since the HAZ is very small and the heat is taken away rapidly. In previous studies [39] thermal cameras or infrared radiation measuring instruments were used for the determination of the temperature distribution in the weld seam, although in many cases only the surface temperature of the transparent component is used to draw conclusions about the real temperature distribution inside the weld seam.

The experimental setup (Figure 9) shows the used measurement technology for the determination of the maximum temperature in the weld seam. During the experiment the objective of the thermal camera is positioned in a distance of $10 \mathrm{~cm}$ from the surface of the sample. The emissivity of the PA66 sample is approximated as $\varepsilon=0.95$. Since the measurement is performed without the laser transparent component, the adjusted laser power is reduced by the reduction of the transmission. For this purpose the nominal laser output of the welding system is set to the power which has been calculated in the simulation after the penetration of transparent component based on the optical properties of the material. Possible beam expansions, which lead to distortion of the laser beam when penetrating the transparent component, are neglected in this experimental setup. The thermal camera type A655 of Flir Systems, Wilsonville, Oregon, USA, has a recording rate of $50 \mathrm{~Hz}$ and the thermal resolution exceeds $30 \mathrm{mK}$. To provide a statistical reliability of the results each measurement is replicated three times.

The average standard deviation between the calculated and measured temperatures is $26.43 \%$. In average, temperatures higher than $485^{\circ} \mathrm{C}$ are measured in the weld seam. According to the safety data sheet the thermal decomposition of the polymer starts at $320^{\circ} \mathrm{C}$ [40]. In microscopy one cannot determine thermal decomposition in the weld seam for most of the samples, although the decomposition temperature is exceeded. The phenomenon that polymers can shortly be heated above the decomposition temperature has already been discussed in earlier studies. Russek explains the high temperatures in the weld seam with the Arrhenius law, which deals with the temperature dependence of the speed of a reaction [9]. Although polymers start to decompose with high temperatures this effect does not directly occur when exceeding the decomposition temperature. Only after a determined retention time above the decomposition temperature did irreversible decompositions occur. Thus the retention time of a polymer temperature decreases exponentially with the temperature above the decomposition, while the degradation rate increases equally [41]. The absence of oxygen in the welding zone due to the welding pressure additionally supports a longer retention time.

As shown in Table 1, the measured temperatures in most cases are higher than the simulated temperatures. The measurement of higher temperatures on the surface of the absorbing component in comparison to the simulation can be explained by the fact that the transparent component is absent. The power that impacts the absorbing component is adjusted by the transmission and reflection factor of the transparent part. However, the beam expansion of the laser focus, due to the penetration of the upper component, is not considered in the measurement. Additionally there is a risk that the frame rate of $50 \mathrm{~Hz}$ is not able to capture the maximum temperature. Measurements with short welding times at high power show a low reproducibility. The accuracy of this measuring method increases with the welding time. The development of the temperature along the length of the $\mathrm{HAZ}$ of the three measurements (at $t_{B}=0.1 \mathrm{~s}$ ) is shown in Figure 8 .

Overall the approach of measuring the temperature using a thermal camera on the absorbing component is a suitable method for obtaining at least an indication of the resulting temperatures in the HAZ. To achieve even better results and 
TABLE 1: Comparison of the measured temperatures in the "heat affected zone" and the maximum temperature in the simulation.

\begin{tabular}{lccc}
\hline Time $t_{L}[\mathrm{~s}] /$ power $P_{L}[\mathrm{~W}]$ & Measured temperature $\left[{ }^{\circ} \mathrm{C}\right]$ & Standard deviation [\%] & Simulated temperature $\left[{ }^{\circ} \mathrm{C}\right]$ \\
\hline $0.1 / 160$ & 419.53 & 47.08 & 320.86 \\
$0.25 / 70$ & 417.42 & 10.57 & 286.34 \\
$0.25 / 90$ & 471.89 & 26.32 & 362.00 \\
$0.25 / 120$ & 503.42 & 21.54 & 476.00 \\
$0.5 / 50$ & 485.71 & 26.96 & 303.39 \\
$0.5 / 70$ & 522.75 & 8.13 & 418.05 \\
$0.5 / 90$ & 500.09 & 14.4 & 532.98 \\
$0.75 / 50$ & 498.80 & 5.98 & 367.76 \\
$0.75 / 70$ & 498.55 & 3.34 & 510.95 \\
$1.00 / 50$ & 537.88 & 4.11 & 419.45 \\
\hline
\end{tabular}

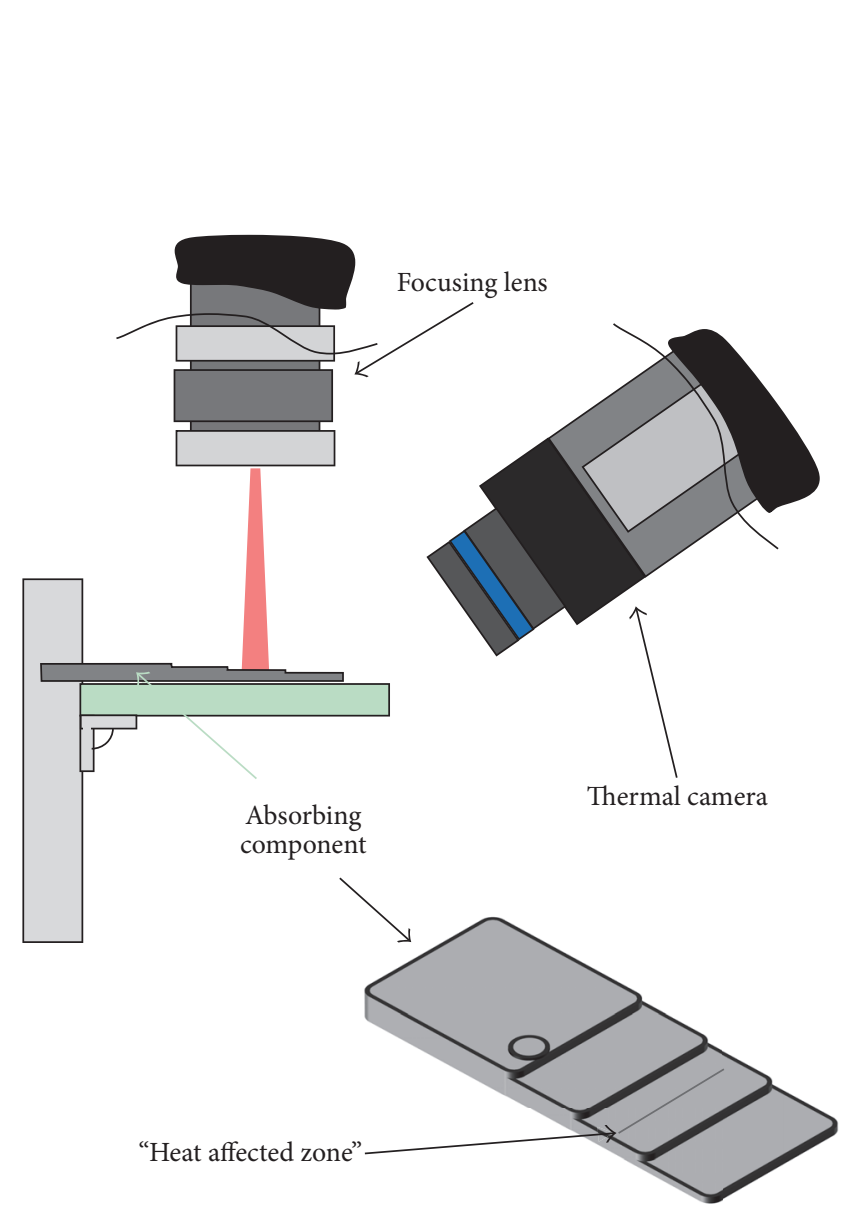

(a)

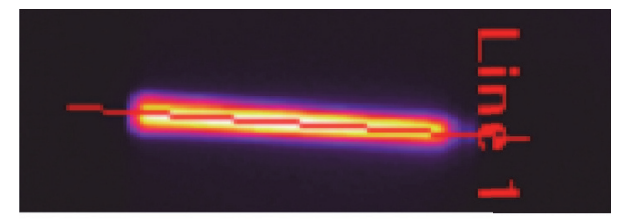

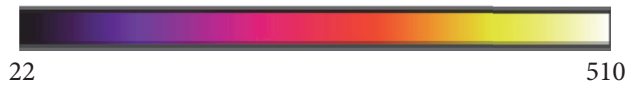

$\left({ }^{\circ} \mathrm{C}\right)$

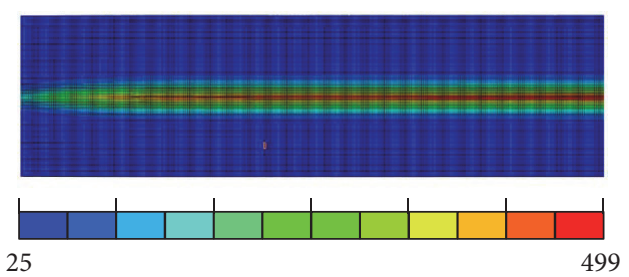

$\left({ }^{\circ} \mathrm{C}\right)$

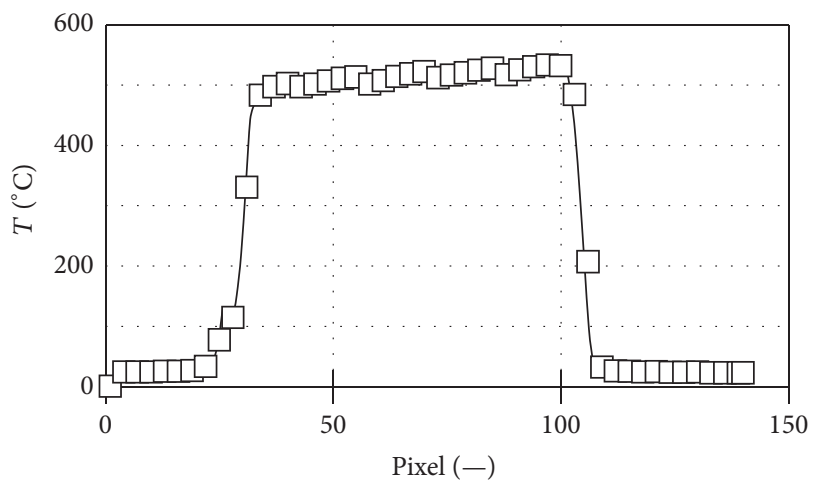

(b)

FIGURE 9: Measuring setup for the determination of the temperature (a) and the comparison of the calculated and measured values (b).

to increase the reproducibility with short welding times and high laser intensities the performed measurements should be repeated with a high speed thermal camera.

\section{Conclusions and Perspective}

A successful implementation of the spatial temperature distribution between the welding partners has been performed and added to the simulation model. With the reliable thermal simulation model for the visualization of the heating of the joining areas one is able to predict the required laser power and the achievable process times for the process variant simultaneous welding. For the transfer to additional materials it is necessary to determine the material properties as well as the distribution of the laser output density. In further studies the developed model has to be specified, whereby a high 
priority should be assigned to the determination of the provided energy density.

\section{Competing Interests}

The authors certify that they have no affiliations with or involvement in any organization or entity with any financial interest (such as honoraria; educational grants; participation in speakers' bureaus; membership, employment, consultancies, stock ownership, or other equity interest; and expert testimony or patent-licensing arrangements) or nonfinancial interest (such as personal or professional relationships, affiliations, knowledge, or beliefs) in the subject matter or materials discussed in this manuscript.

\section{Acknowledgments}

The research Project 17509N of the Forschungsvereinigung Kunststoffverarbeitung was sponsored as part of the "Industrielle Gemeinschaftsforschung und Entwicklung (IGF)" by the German Bundesministerium für Wirtschaft und Energie (BMWi) due to an enactment of the German Bundestag through the AiF. The authors would like to extend their thanks to all organizations mentioned. The authors are very grateful to BASF SE, Ludwigshafen, Germany, and Borealis AG, Vienna, Austria, who supported the research with test materials and technical support. Furthermore, they would like to thank Firma Primes GmbH, Pfungstadt, Germany, and Ophir Optronics Solutions Ltd., Jerusalem, Israel, for technical support for the measurement systems.

\section{References}

[1] J. Klein and A. Kraus, "Ist das Laserstrahlschweißen wirtschaftlich?” Kunststoffe, vol. 94, no. 7, pp. 49-51, 2004.

[2] K. Lenfert, S. Hierl, and F. Brunnecker, "Schritt für Schritt oder alles zugleich," Plastverarbeiter, vol. 53, no. 5, pp. 34-35, 2002.

[3] B. Geißelmann, S. Hierl, and K. Lenfert, "Perfekt verschlossen," Plastverarbeiter, vol. 55, no. 11, pp. 74-75, 2004.

[4] J. Korte, Laserschweißen von Thermoplasten [Dissertation], Universität-GH Paderborn, 1998.

[5] H. Klein, Laserschweißen von Kunststoffen in der Mikrotechnik [Dissertation], RWTH Aachen, 2001.

[6] Y. C. Kennish, H. R. Shercliff, and G. C. McGrath, "Heat flow model for laser welding of polymers," in Proceedings of the 60th Annual Technical Conference of the Society of Plastics Engineers (ANTEC '02), pp. 1132-1136, San Francisco, Calif, USA, 2002.

[7] J. Schulz, Werkstoff-, Prozess- und Bauteiluntersuchungen zum Laserdurchstrahlschweißen von Kunststoffen [Dissertation], RWTH Aachen University, Aachen, Germany, 2002.

[8] Y. C. Kennish, Development and modelling of a new laser welding process for polymers [thesis], University of Cambridge, Cambridge, UK, 2003.

[9] U. A. Russek, Prozesstechnische Aspekte des Laserdurchstrahlschweißens von Thermoplasten [Dissertation], RWTH Aachen University, Aachen, Germany, 2006.

[10] F. Becker, Einsatz des Laserdurchstrahlschweißens zum Fügen von Thermoplasten [thesis], Universität-GH Paderborn, Paderborn, Germany, 2003.
[11] G. Fiegler, Ein Beitrag zum Prozessverständnis des Laserdurchstrahlschweißens von Kunststoffen anhand der Verfahrensvarianten Quasi-Simultan- und Simultanschweißen [Dissertation], Universität Paderborn, Paderborn, Germany, 2007.

[12] T. Frick, Untersuchung der prozessbestimmenden Strahl-StoffWechselwirkungen beim Laserstrahlschweißen von Kunststoffen [thesis], Friedrich-Alexander-Universität Erlangen-Nürnberg, Erlangen, Germany, 2007.

[13] M. Fargas, L. Wilke, O. Meier, and H. Potente, "Analysis of weld seam quality for laser transmission welding of thermoplastics based on fluid dynamical processes," in Proceedings of the 65th Annual Technical Conference of the Society of Plastics Engineers (ANTEC '07), Cincinatti, Ohio, USA, May 2007.

[14] L. S. Mayboudi, A. M. Birk, G. Zak, and P. J. Bates, "Laser transmission welding of a lap-joint: thermal imaging observations and three-dimensional finite element modeling," Journal of Heat Transfer, vol. 129, no. 9, pp. 1177-1186, 2007.

[15] M. Ilie, J.-C. Kneip, S. Matteï, A. Nichici, C. Roze, and T. Girasole, "Through-transmission laser welding of polymerstemperature field modeling and infrared investigation," Infrared Physics \& Technology, vol. 51, no. 1, pp. 73-79, 2007.

[16] D. Grewell and A. Benatar, "Semiempirical, squeeze flow, and Lntermolecular diffusion model. II. Model verification using laser microwelding," Polymer Engineering \& Science, vol. 48, no. 8, pp. 1542-1549, 2008.

[17] L. S. Mayboudi, A. M. Birk, G. Zak, and P. J. Bates, "Infrared observations and finite element modeling of a laser transmission welding process," Journal of Laser Applications, vol. 21, no. 3, pp. 111-118, 2009.

[18] T. Zoubeir and G. Elhem, "Numerical study of laser diode transmission welding of a polypropylene mini-tank: temperature field and residual stresses distribution," Polymer Testing, vol. 30, no. 1, pp. 23-34, 2011.

[19] B. Acherjee, A. S. Kuar, S. Mitra, and D. Misra, "Modeling of laser transmission contour welding process using FEA and DoE," Optics \& Laser Technology, vol. 44, no. 5, pp. 1281-1289, 2012.

[20] S. Sooriyapiragasam and C. Hopmann, "Modeling of the heating process during the laser transmission welding of thermoplastics and calculation of the resulting stress distribution," Welding in the World, vol. 60, no. 4, pp. 777-791, 2016.

[21] G. W. Ehrenstein, Handbuch Kunststoff-Verbindungstechnik, Carl Hanser, München, Germany, 2004.

[22] H. Potente, Fügen von Kunststoffen-Grundlagen, Verfahren, Anwendungen, Carl Hanser, München, Germany, 2004.

[23] J. Hopmann and S. Sooriyapiragasam, "Prozessmodellierung des Erwärmvorgangs beim Laserdurchstrahlschweißen von Kunststoffen," Joining Plastics, vol. 8, no. 3-4, pp. 170-177, 2014.

[24] H. Jundt, "Schweißen in allen Formen," Plastverarbeiter, vol. 57, no. 4, pp. 88-89, 2006.

[25] M. Aden, A. Rösner, and A. Olowinsky, "Optical characterization of polycarbonate: influence of additives on optical properties," Journal of Polymer Science-Part B: Polymer Physics, vol. 48, no. 4, pp. 451-455, 2010.

[26] X. F. Xu, P. J. Bates, and G. Zak, "Effect of glass fiber and crystallinity on light transmission during laser transmission welding of thermoplastics," Optics \& Laser Technology, vol. 69, pp. 133-139, 2015.

[27] R. Lützeler, Laserdurchstrahlschweißen von teilkristallinen Thermoplasten [Dissertation], RWTH Aachen University, Aachen, Germany, 2005. 
[28] M. Devrient, X. Da, T. Frick, and M. Schmidt, "Experimental and simulative investigation of laser transmission welding under consideration of scattering," Physics Procedia, vol. 39, pp. 117-127, 2012.

[29] M. Hohmann, M. Devrient, F. Klämpfl, S. Roth, and M. Schmidt, "Simulation of light propagation within glass fiber filled thermoplastics for laser transmission welding," Physics Procedia, vol. 56, pp. 1198-1207, 2014.

[30] C. Hopmann and S. Sooriyapiragasam, "Simulation of the heat process in laser transmission welding," in Proceedings of the International Institute of Welding (IIW '13), Essen, Germany, 2013.

[31] S. Sooriyapiragasam and C. Hopmann, "Modelling of the heating process during the laser transmission welding of thermoplastics and calculation of the resulting stress distribution," in Proceedings of the International Institute of Welding (IIW '15), Helsinki, Finland, 2015.

[32] W. Plass, R. Maestle, K. Wittig, A. Voss, and A. Giesen, "Highresolution knife-edge laser beam profiling," Optics Communications, vol. 134, no. 1-6, pp. 21-24, 1997.

[33] J. F. Ready, K. Nagarathnam, and J. Mazumder, LIA Handbook of Laser Materials Processing, Laser Institute of America, Orlando, Fla, USA, 2001.

[34] F. Becker and H. Potente, "A step towards understanding the heating phase of laser transmission welding in polymers," Polymer Engineering and Science, vol. 42, no. 2, pp. 365-374, 2002.

[35] E. Haberstroh, J. Schulz, and R. Lützeler, “Thermographic characterisation of polymers for the laser transmission welding," in Proceedings of the 59th Annual Technical Conference (ANTEC '01), San Francisco, Calif, USA, 2001.

[36] H. Haferkamp, A. von Busse, M. Hustedt, J. Bunte, E. Haberstroh, and R. Lützeler, "Utilisation of a thermographic process in order to determine the laser weldability of plastics at different wavelengths," Welding and Cutting, vol. 1, no. 3, pp. 43-49, 2004.

[37] G. Zak, L. Mayboudi, M. Chen, P. J. Bates, and M. Birk, "Weld line transverse energy density distribution measurement in laser transmission welding of thermoplastics," Journal of Materials Processing Technology, vol. 210, no. 1, pp. 24-31, 2010.

[38] Datenblatt der Spiricon Sp620U. Technische Beschreibung, Ophir Optronics Solutions, Ophir Optronics Solutions, Jerusalem, Israel, 2015.

[39] L. S. Mayboudi, Heat transfer modelling and thermail imaging experiments in laser transmission welding of thermoplastics [Dissertation], Queen's University, Kingston, Canada, 2008.

[40] Sicherheitsdatenblatt, BASF SE, Ludwigshafen, Germany, 2015.

[41] G. Menges, E. Haberstro, W. Michaeli, and E. Schmachtenberg, Werkstoffkunde Kunststoffe, Carl Hanser, München, Germany, 2002.

[42] Original Betriebsanleitung Focus-Monitor/BeamMonitor, Technische Beschreibung, Primes, Pfungstadt, Germany, 2013. 

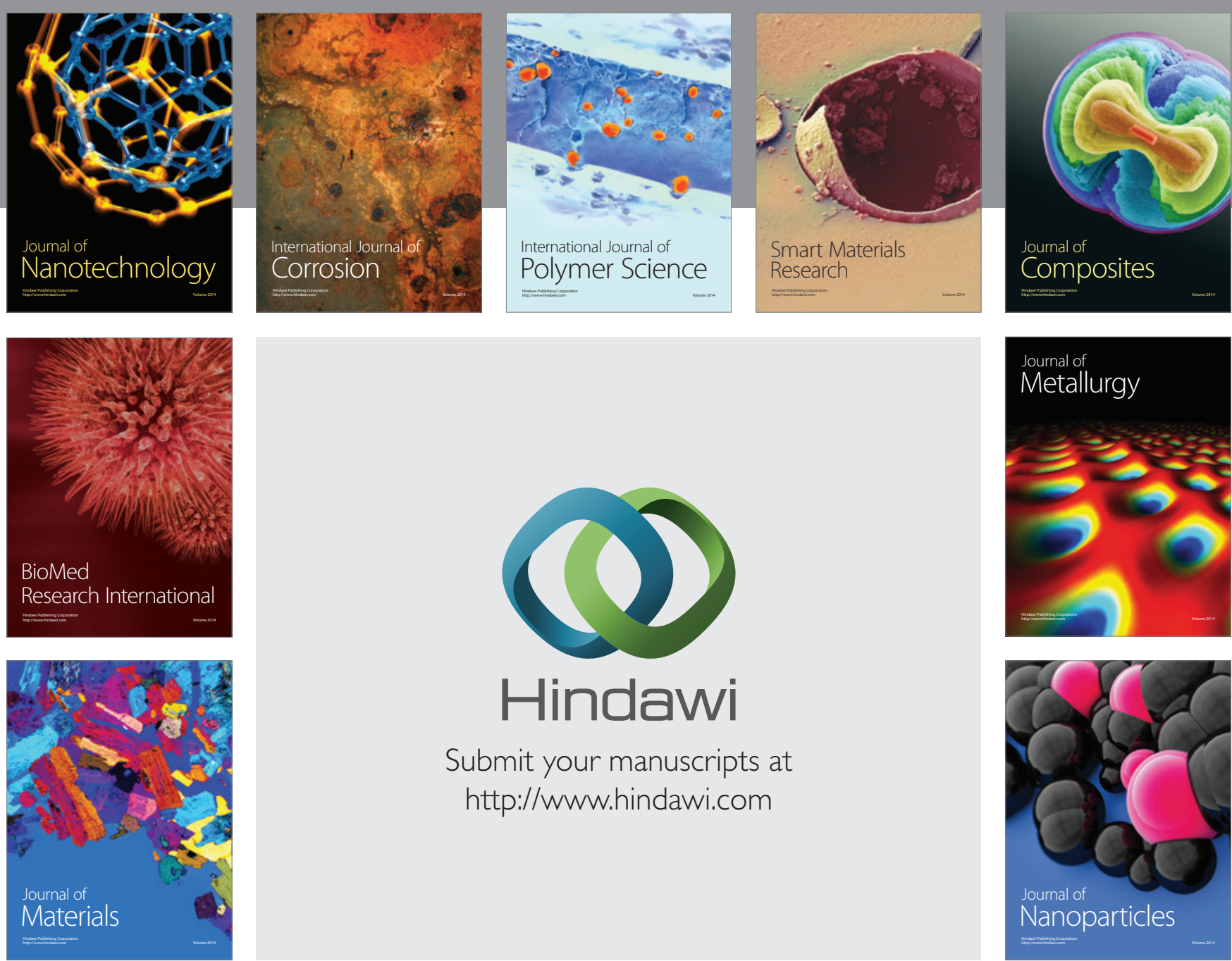

\section{Hindawi}

Submit your manuscripts at

http://www.hindawi.com

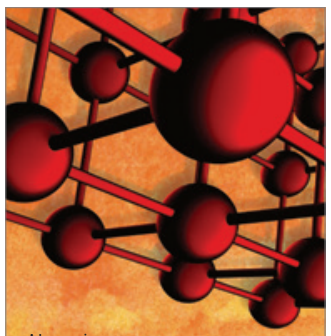

Materials Science and Engineering
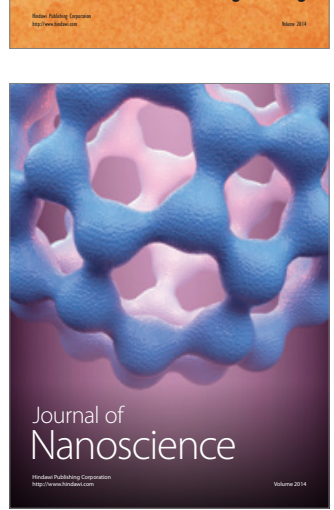
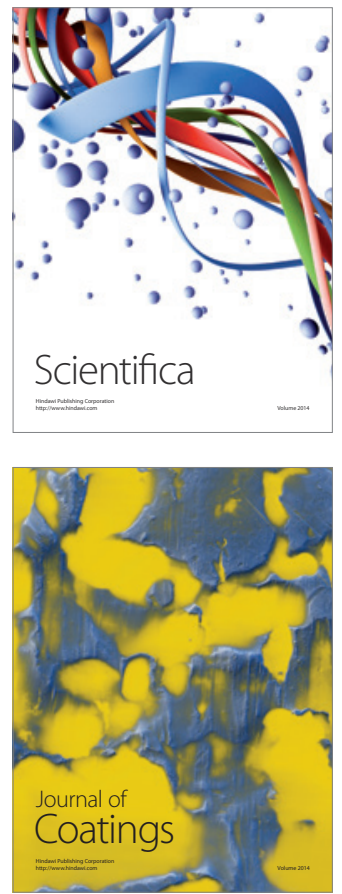
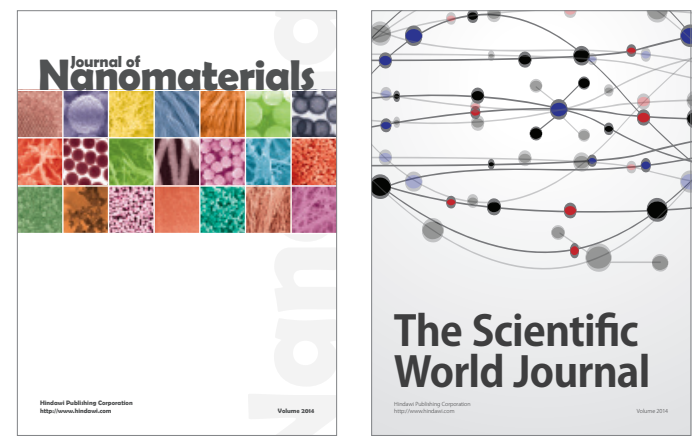

The Scientific World Journal
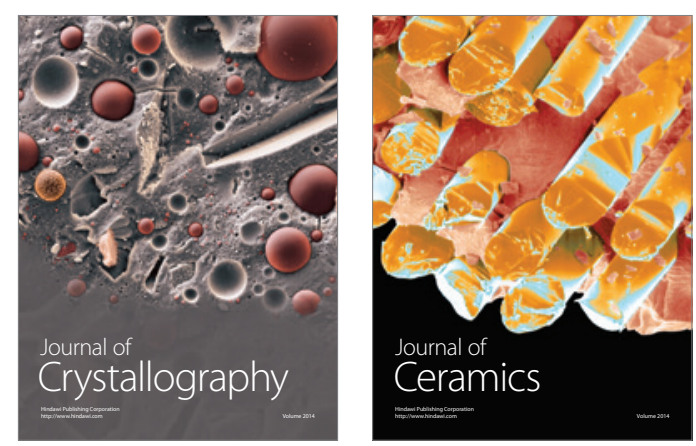
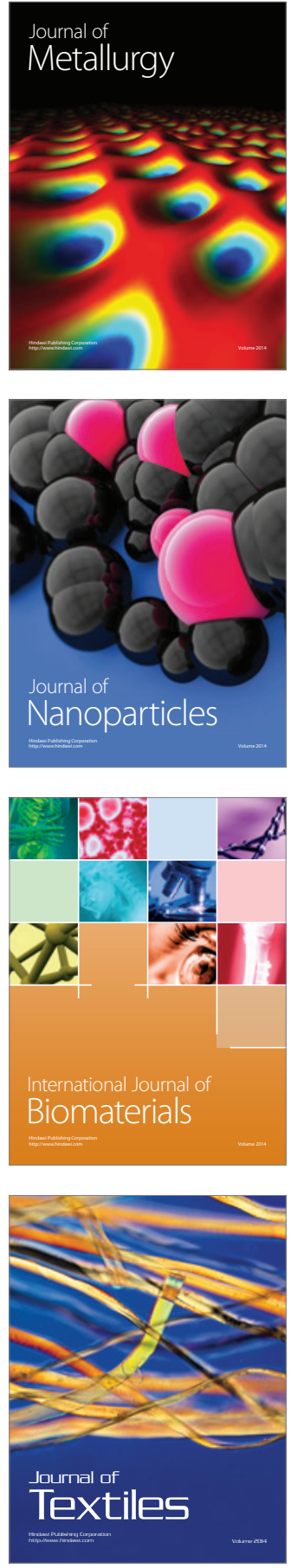